\title{
Liver abscess and disseminated intravascular coagulation in tuberculosis
}

\author{
MRN Nampoory, MMA Halim, R Sreedharan, NAS Al-Sweih, RK Gupta, \\ JN Constandi, KV Johny
}

\begin{abstract}
Summary
We report the case of a 55-year-old man with chronic renal failure, and a history of prolonged fever and jaundice. Radiological studies revealed a multiloculated irregular liver abscess. Mycobacterium tuberculosis was isolated from the abscess on smear and culture of aspirated pus. Haematological studies revealed the presence of disseminated intravascular coagulation. A detailed search failed to identify any reason for this other than the tuberculous infection. The treatment of tuberculous liver abscess and pathogenesis of disseminated intravascular coagulation in tuberculosis are discussed.
\end{abstract}

Keywords: liver abscess, tuberculosis, disseminated intravascular coagulation

Tuberculous liver abscesses are rare and are usually associated with foci of infection in the lung or gastrointestinal tract. ${ }^{1}$ Isolated hepatic tuberculous abscesses are even rarer and only 14 cases have been reported in the English literature to date. ${ }^{2}$ Diagnosis has been difficult in most instances and is usually made at post mortem. ${ }^{3}$ Development of disseminated intravascular coagulation is unusual in tuberculosis, although an association with miliary tuberculosis has been described. ${ }^{4}$ In this report, we describe a case of tuberculous liver abscess complicated

Department of Medicine, Radiology and Microbiology, Mubarak Al-Kabeer Hospital, Ministry of Public Health, Kuwait MRN Nampoory

MMA Halim

R Sreedharan

NAS Al-Sweih

RK Gupta

JN Constandi

Department of Medicine, Faculty of Medicine, Kuwait University, Kuwait KV Johny

Correspondence to Professor KV Johny Department of Medicine, Faculty of Medicine, PO Box 24923, Safat, 13110 Kuwait.

Accepted 2 March 1995 for the fever. He was advised to undergo a live biopsy, even though the liver enzymes were normal, to search for any obscure granu- lomatous disease. He refused the procedure and was discharged from the hospital.

$\mathrm{He}$ continued to have fever and was readmitted in November 1993 having had moderate melaena for two days prior to admission. On examination he was stuporous, anaemic, febrile $\left(38.5^{\circ} \mathrm{C}\right)$, mildly volume depleted and acidotic. He had no evidence of cutaneous or other bleeding sites. His blood pressure was 130/ $80 \mathrm{mmHg}$. Examination of his respiratory system revealed basal fine crepitations posteriorly on the right side. Cardiovascular, gastrointestinal, neurological, musculoskeletal and optic fundus examination did not reveal any abnormal findings. Investigations done at this time revealed the following results: white blood cells $8.7 \times 10^{9} / 1$, haemoglobin $7.1 \mathrm{~g} / \mathrm{dl}$, packed cell volume $19.9^{\circ}$, platelets $50 \times 10^{\%} / 1$, peripheral blood film showed schistocystosis and fragmented erythrocytes, prothrombin time $18 \mathrm{~s}$ (control $12 \mathrm{~s}$ ) (INR: 1.59), partial thromboplastin time $85 \mathrm{~s}$ (control $30 \mathrm{~s}$ ), thrombin time $20 \mathrm{~s}$ (control $18 \mathrm{~s}$ ), fibrinogen $3.5 \mathrm{~g} / \mathrm{l}$ (normal $2-4 \mathrm{~g} / \mathrm{l}$ ), fibrin degradation product $40 \mathrm{mg} / 1$ (normal $<10 \mathrm{mg} / \mathrm{l}$ ), blood sugar $5.8 \mathrm{mmol} / \mathrm{l}$, blood urea $42 \mathrm{mmol} / \mathrm{l}$, serum creatinine $658 \mu \mathrm{mol} / \mathrm{l}$, potassium $6.8 \mathrm{mmol} / \mathrm{l}$, bicarbonate $10.2 \mathrm{mmol} / \mathrm{l}$, sodium $130 \mathrm{mmol} / \mathrm{l}$, chloride $106 \mathrm{mmol} / 1$, serum amylase $500 \mathrm{IU} / \mathrm{l}$, calcium $2.1 \mathrm{mmol} / 1$, phosphorus $1.6 \mathrm{mmol} / 1$, alkaline phosphatase $789 \mathrm{IU} / 1$ (normal: $35-$ 85), aspartate transaminase $94 \mathrm{IU} / 1$ (normal 5-37), alanine transaminase $40 \mathrm{IU} / 1$ (normal 5-40), $\gamma$-glutamyl transaminase $108 \mathrm{IU} / 1$ (normal 7-64), and total bilirubin $29 \mu \mathrm{mol} / \mathrm{l}$. Blood, urine, and throat swab cultures did not reveal any significant microorganism. Microbiological and virological studies of cerebrospinal fluid (CSF) were all negative for any pathogen. Chest X-ray revealed a few fluffy shadows in the right base. Computed tomography (CT) of brain did not reveal any abnormal findings. In view of his clinical picture, nationality and nature of work in a pulmonary ward, a trial of anti-tuberculous treatment with INAH, pyrazinamide and rifampicin was started. Bronchoscopic evaluation 48 hours later revealed inflammation of the right lower lobe and its bronchus. A bronchial lavage did not grow any bacteria, fungus or virus and smear revealed acid-fast bacilli. Upper gastrointestinal endoscopy revealed a bleeding duodenal ulcer which necessitated eight blood transfusions, and use of omeprazole and pepsidin. Disseminated intravascular coagulation 
was managed with fresh frozen plasma and platelet transfusions. In addition he was started on regular haemodialysis.

Ten days after admission (seven days after starting antituberculous treatment he was clinically icteric with tender hepatomegaly. The liver function tests then revealed total bilirubin $167 \mathrm{mmol} / \mathrm{l}$ (direct 88 , indirect 79) and alkaline phosphatase $350 \mathrm{IU} / 1$ while aspartate transaminase and alanine transaminase were normal. His serum albumin was $32 \mathrm{~g} / 1$ while prothrombin time and partial thromboplastin time had improved to $16 \mathrm{~s}$ (control $12 \mathrm{~s}$ ) and $40 \mathrm{~s}$ (control $32 \mathrm{~s}$ ), respectively. An abdominal ultrasonogram revealed a right lobe liver abscess with loculations and septations. The gall bladder, common bile duct, pancreas and spleen were normal. CT of the abdomen confirmed a liver abscess of $10 \times 13 \times 7 \mathrm{~cm}$ irregular, multiloculated and hypoechoic (figure). A percutaneous drain was done under ultrasound guidance after adequate correction of bleeding parameters and thick pus and necrotic tissue were obtained. A proper closed drainage was impossible since there were septations, loculations and poor breakdown of the lesion. A direct smear of this pus revealed numerous acid-fast bacilli. There were no bacteria or fungal hyphae and culture grew mycobacterium tuberculosis. $\mathrm{He}$ was continued on anti-tuberculous drugs because of apparent improvement in liver function tests except for bilirubin. Dialysis and other supportive measures like blood transfusions and parenteral nutrition were continued. In spite of these measures his clinical condition deteriorated. His liver function also worsened progressively and the laboratory results on the 30 th day of admission revealed a total bilirubin of $435 \mu \mathrm{mol} / 1$, direct bilirubin $162 \mu \mathrm{mol} / 1$, aspartate transaminase $94 \mathrm{IU} / 1$, alanine transaminase $40 \mathrm{IU} / 1$, alkaline phosphatase $599 \mathrm{IU} / 1$ (heat stable being $436 \mathrm{IU} / 1$ ), $\gamma$-glutamyl transaminase $95 \mathrm{IU} / \mathrm{l}$, serum albumin $16 \mathrm{~g} / \mathrm{l}$ and serum ammonia $102 \mu \mathrm{mol} / 1$. Anti-hepatic coma measures were added to the therapeutic regime but his condition progressively worsened and he expired on the 34th day of admission.

\section{Discussion}

Diffuse liver involvement is frequently encountered in patients suffering from tuber-

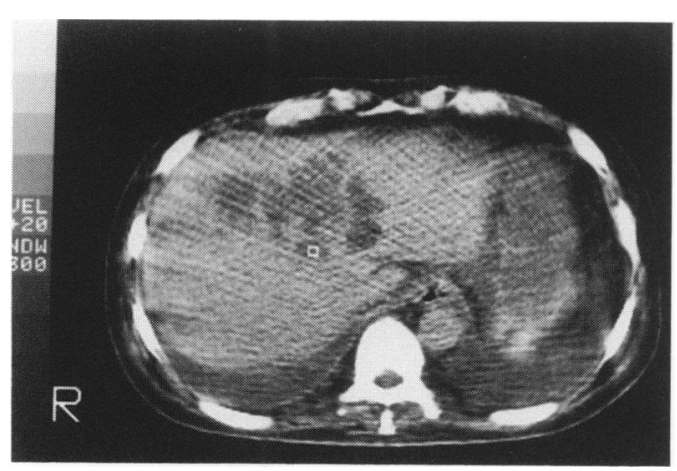

Figure CT scan of upper abdomen demonstrating irregular hypoechoeic, multiloculated liver abscess $(10 \times 13 \times 7 \mathrm{~cm})$ culosis. A review of indexed literature since 1930 included 444 reported cases of tuberculosis of liver. ${ }^{5}$ Liver biopsy specimens show non-caseating granulomas in $25 \%$ of patients with pulmonary tuberculosis and $80 \%$ of patients with extrapulmonary tuberculosis. ${ }^{6}$ Three forms of tuberculous liver involvement are described (see box). ${ }^{3}$

Tuberculous liver abscess was probably first described by Bestowe in $1858 .^{3}$ Leader et al collected 80 cases up to $1952^{1}$ and Stevens ${ }^{3}$ concluded that less than 100 cases had been described up to 1987. Since then seven more cases have been described in english-language medical literature..$^{2,5-10}$

Tuberculous liver abscess is usually secondary to primary pulmonary or gastrointestinal involvement. ${ }^{2}$ When there is no gut involvement, the route by which mycobacteria reach the liver could be the hepatic artery during systemic mycobacteremia from the lung. The immunologic status of the host and the load of bacilli are recognised as factors that influence the pathogenic pattern of infection. This could explain the occurrence of tuberculous liver abscess in our patient since uremia is an immuno-depressed state. Following the first description of AIDS, three cases of tuberculous liver abscess have been described in the literature.$^{8-10}$ Tuberculous liver abscess occurs most frequently in children and in racial groups felt to have reduced natural immunity. ${ }^{3}$ Our patient fits into the latter high-risk group.

High fever, weight loss, right hypochondrial pain and hepatomegaly are the most frequently observed clinical findings. ${ }^{2}$ Our patient had all four features. Jaundice is a rare manifestation in tuberculous liver abscess and may be caused by extra or intrahepatic obstruction. " Our patient had jaundice associated with a rise in alkaline phosphatase, similar to the case reported by Silverberg et al. ${ }^{13}$ No clear relationship exists between the degree of liver involvement and jaundice. ${ }^{12}$ Tuberculous liver abscess is frequently confused with hepatoma, amoebic or pyogenic liver abscess and differentiation is frequently difficult such that one group labeled this entity as a 'pseudotumour' of the liver. ${ }^{14}$

Since the clinical findings are non-specific, the diagnosis of hepatic abscess is often made at autopsy or at laparotomy. There is no specific radionucleide imaging appearance that is characteristic. ${ }^{14}$ Ultrasonographic and CT finding of multiple septated ('honeycombed-like') liver abscess was described by Wilde and Kueh." Our patient had similar ultrasonographic and CT findings. Ultimate diagnostic confirmation

Liver involvement in tuberculosis

- diffuse involvement associated with miliary or pulmonary tuberculosis

- diffuse parenchymal involvement without any evidence of existing tuberculosis elsewhere (primary miliary tuberculosis of the liver)

- focal or nodular lesion in liver which may be multiple or solitary and present as tuberculoma or abscess 


\section{Treatment options in tuberculous} liver involvement

- medical - oral antituberculous treatment

- local infusion of isoniazid and rifampicin 6 hourly through an indwelling catheter

- surgical - ultrasonographic or CT-guided aspiration and drainage of abscess

- open surgical drainage of abscess

is by demonstrating acid-fast mycobacterium in the aspirated pus or necrotic tissue on smear or culture, as in our patient. When this is not successful histological examination of the abscess wall may be required for confirmation.

Medical treatment of a tuberculous liver abscess is still a debated subject. Even though success has been reported with oral antituberculous drugs alone, prognosis is poor in most cases. ${ }^{6,8}$ Of interest is the formation of an abscess reported even after starting chemotherapy. ${ }^{2}$ Gracey postulates that the thick fibrous tissues around the abscess and their large size may prevent antibiotics from reaching their target..$^{15}$ Mustard et al have recommended local infusion of isoniazid and rifampicin every six hours through an indwelling catheter to overcome this problem. ${ }^{16}$ Even though surgical drainage was used earlier in management, presently either sonographic or CT-guided aspiration or drainage is found to

1 Leader SA. Tuberculosis of liver and gall bladder with abscess formation. A review and case report. Ann Intern Med 1952; 37: 594-606.

2 Reed DH, Nash AF, Valabhji P. Radiological diagnosis and management of a solitary tuberculous hepatic abscess. $\mathrm{Br} \mathcal{F}$ Radiol 1990; 63: 902-4.

3 Stevens A, Little JM. Isolated tuberculous hepatic abscess. Aust NZ ₹ Surg 1987; 57: 409-11.

4 Mavligit GM, Bender RA, Crosby WHC. Disseminated intra-vascular coagulation in miliary tuberculosis. Arch Intern Med 1972; 130: 388-9.

5 Wilde CC, Kueh YK. Case report: tuberculous hepatic and splenic abscess. Clin Radiol 1991; 43: 215-6.

6 Desmidt $P$, Apfelbaum $M$, Holvoet J, Huben $H$ Haber

Desmidt $P$, Apfelbaum M, Holvoet J, Huben H, Haber 378-80.

7 Fernandez-Miyanda C, Perpina C, Kessler P, Torres N,

Manjon P, de la Calle A. Hepatosplenic tuberculous Manjon $P$, de la Calle $\mathrm{A}$. Hepatosplenic tuberculous
abscesses in a patient with polyarteritis nodosa. $A m \mathcal{F}$ abscesses in a patient with poly

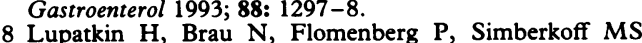
Tuberculous abscesses in patients with AIDS. Clin Infect Dis 1992; 14: 1040-4.

9 Moreno S, Pacho E, Loez-Herce JA, Rodriguez-Creixems M, Martin Scapa C, Bouza E. Mycobacterium tuberculosis visceral abscesses in the acquired immunodeficiency syndrome (AIDS). Ann Intern Med 1988; 109: 437. be equally successful. ${ }^{2}$ Failure of treatment in our case was most probably due to inadequate penetration of drugs to the abscess region. However, drug-related hepatotoxicity may have contributed.

An association between miliary tuberculosis and development of disseminated intravascular coagulation, although rare, has been documented. ${ }^{17}$ The pathogenesis of disseminated intravascular coagulation is still not clear since mycobacteria are not known to produce either endotoxins or exotoxins that can initiate the clotting cascade. Initiation of disseminated intravascular coagulation by tuberculoprotein in miliary tuberculosis is only a matter of conjecture. ${ }^{18}$ In our patient, the diagnosis of disseminated intravascular coagulation was based on low platelet count, prolonged prothrombin and activated partial thromboplastin time, increased fibrin degradation products and the presence of schistocytes and fragmented erythrocytes in the peripheral blood smear. Careful and detailed investigations had failed to detect any other type of infection. However, the presence of mycobacteria in pus aspirated from the liver and in bronchial lavage had confirmed disseminated tuberculosis. Liver functions were normal initially when the patient presented with disseminated intravascular coagulation and hepatic dysfunction developed only subsequently. Thus the causative relationship between disseminated intravascular coagulation and tuberculosis would seem highly probable in this patient.

10 Weinberg JJ, Cohen P, Malhotra R. Primary tuberculous liver absess associated with the human immuno-deficiency liver abscess associated with the
virus. Tubercle 1988; 69: 145-7.

11 Morris E. Tuberculosis of liver. Am Rev Tuberculosis 1930 22: 585 .

12 Chariklia TS, Carmelita UT. Tuberculous liver abscess. Tubercle 1984; 65: 127-31.

13 Silverberg LF, Johnston C, Haber T. Tuberculous involvement of a polymicrobial liver abscess. West $\mathcal{F}$ Med 1984; 141 682-5.

14 Dhekne RD, Moore WH, Long SE, Barron BJ. Tuberculou pseudotumor of the liver. Clin Nucl Med 1987; 12: 816-9.

15 Gracey L. Tuberculous abscess of the liver. Br f Surg 1965; 52: 442-3.

16 Mustard RA, Mackenzie RL, Gray RG. Percutaneous drainage of a tuberculous liver abscess. Can f Surg 1986; 29: 449-50.

17 Manzella JP, Kellog J, Sanstead JK. Myobacterium tuberculosis bacteremia and disseminated coagulation. $\mathfrak{f} A M A$ culosis bacteremia

18 Eliopoulos G, Vaiopoulos G, Kittas C, Fessas P. Tuberculosis associated hemophagocytic syndrome complicated with severe bone marrow failure and disseminated intravascular coagulation. Nouv Rev Fr Haematol 1992; 34: 273-6. 